\title{
Formulation and Evaluation of Herbal Lotion of Aloe Vera (Aloe Barbadensis)
}

Harshita Verma*, Dr. Dharmesh Sisodiya

Assistant Professor of Institute of Pharmacy Vikram University, Ujjain

DOI: $10.36347 /$ sajb.2020.v08i01.002

| Received: 19.11.2019 | Accepted: 26.11.2019 | Published: 18.01.2020

*Corresponding author: Harshita Verma

\section{Abstract}

\section{Original Research Article}

Aloe vera is oldest medicinal plant ever known and the most applied medicinal plant worldwide. Several steps used in formulation of lotion such as cutting of tip and base of the leaf, extract mucilage part in mixing jar grind it well, add vitamin E, pasteurized the mixture and cool it after that gel was prepared further take the measured quantity of the gel for lotion formulation mix the measured quantity of ingredient including gel after some time lotion was prepared. The formulation greenish in color having $\mathrm{pH} 5.5$ easily spreadable and excellent extrudability. The herbal formulation had no adverse effect .It is showed this herbal preparation is useful in inflammation wound healing, anti-tumor, antiaging and so on.

Keywords: Herbal formulation, aloe vera, herbal lotion, herbal gel,wound healing.

Copyright @ 2020: This is an open-access article distributed under the terms of the Creative Commons Attribution license which permits unrestricted use, distribution, and reproduction in any medium for non-commercial use (NonCommercial, or CC-BY-NC) provided the original author and source are credited

\section{INTRODUCTION}

Aloe is also common in both traditional Chinese and Ayurvedic medicine. The name Aloe vera is derived from the Arabic word "Alloeh" meaning "shining bitter substance," while "vera" in Latin means "true" [12]. The plant Aloe vera has a history dating back to biblical times. There are over 250 species of Aloe grown around the world. Only two species are grown commercially: Aloe barbadensis Miller and Aloe arborescens. This plant has been known by a number of names such as "the wand of heaven", "heaven's blessing," and "the silent healer"[9]. Aloe was previously considered in family Liliaceae, but now it has been placed in its own family Aloaceae. Aloe vera has a beneficial effect on human health and can cure many diseases.

Description of Plant:- Habitat-It grows mainly in the dry regions of Africa, Asia, Europe and America. In India, it is found in Rajasthan, Andhra Pradesh, Gujarat, Maharashtra and Tamil Nadu [12]. Geographical Source-Aloes are indigenous to South Africa and South America, but are now cultivated worldwide except in tundra, deserts and rain forests. It takes approximately four years to reach maturity and has a lifespan of about 12 years [10]. Active Ingredient of Plant- Leaves has three layers. The outer most layers consist of 15 - 20 cells thick protective layer synthesizing carbohydrates and proteins [15]. The active components of aloe include anthraquinones, chromones, polysaccharides, and enzymes. The elements $\mathrm{Al}, \mathrm{B}, \mathrm{Ba}$, $\mathrm{Ca}, \mathrm{Fe}, \mathrm{Mg}, \mathrm{Na}, \mathrm{P}, \mathrm{Si}$ etc. has also been reported to be present in Aloe vera.

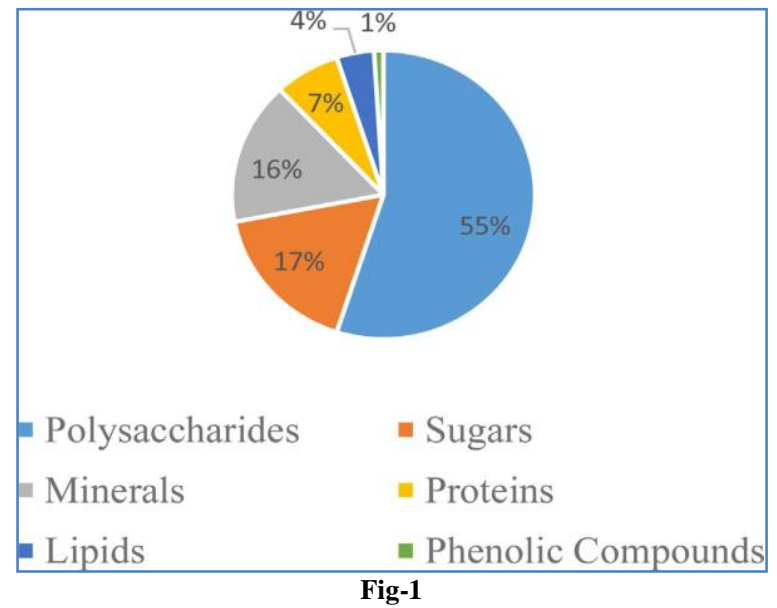

Cultivation:-It is grown successfully in marginal to sub marginal soils having low fertility. The plants have tendency to tolerate high $\mathrm{pH}$ with high $\mathrm{Na}$ and $\mathrm{K}$ salts. The soil should not be disturbed too deep, as the root system of Aloe does not penetrate below 20-30 .It is propagated by root suckers or rhizome cuttings. Aloe can be successfully cultivated both under irrigated and rainfall conditions. Provision of irrigation 
immediately after planting and during summer the plants are sensitive to water logged conditions.

Biological \& Pharmacological Activity of Aloe Vera:- Aloe vera could prevent adjuvant arthritis $72 \%$, and cause a regression of 22 to $26 \%$ at a dosage of 150 $\mathrm{mg} / \mathrm{kg}$ per day. We found that it could reduce edema $80 \%$. keeping the wound moist, increasing epithelial cell reduction in inflammation, It improved skin hydration ,Aloe has excellent anti-aging effect skin more elastic and less wrinkled, Anti Inflammatory Effect,Inhibited the growth of fungi Candida albicans, Laxative Effects-Aloe vera latex possesses laxative to reliance constipation it also used as a purgative, The anti-bacterial effects of Aloe vera extract were bactericidal against 7 of the 12 species of organisms studied, Aloe vera, a great immune stimulant, increases the white blood cells or macrophages and $\mathrm{T}$ cells, Antioxidant Property, Antitumor Effect-The aloe vera gel in terms of reduced tumor burden.

\section{MATERIAL AND METHOD Experimental Work}

Equipment:- Digital balance, $\mathrm{pH}$ meter , measuring cylinder, glass bowl, spoon, Brooke filed viscometer.

\section{Required Material}

Table-1: Materials of formulation

\begin{tabular}{|c|c|c|}
\hline S.No. & Ingredients & Quantity \\
\hline 1. & Aloe vera gel & $150 \mathrm{ml}$ \\
\hline 2. & Coconut oil & $120 \mathrm{ml}$ \\
\hline 3. & Rose water & $240 \mathrm{ml}$ \\
\hline 4. & Vitamin E & 14 capsule \\
\hline 5. & Glycerin & $150 \mathrm{ml}$ \\
\hline 6. & Essential oil & 4 drops \\
\hline 7. & Arrowroot powder & $39 \mathrm{gm}$ \\
\hline
\end{tabular}

Preparation before the formulation: - Clean and sanitize your work area and all you packaging materials. It is suggested that you wear gloves, protective clothing and a hair net while preparing this recipe.

\section{Method of formulation}

\section{- Formulation method of gel:-}

Collect raw material (aloe leaves) Washing leaf and removed base and tip of the leaf, leaf are is cut into section (Filleting) Extract mucilage part of the leaves into mixing jar and Heat it and add agar agar into the mixing jar. Grinding/Homogenization of Unpasteurized Juice Add Vitamin E and Pasteurize the mixer cool the mixer of aloe leaf Packaged the produced gel and Stored it.

\section{Steps Used In Formulation of Gel}

Reception of raw materials- The Aloe vera leaves after harvesting were preferably transported to the processing place. The leaves should be sound, undamaged, mold/rot free and matured (3-4 years) in order to keep all the active ingredients in full concentration.

- Filleting operation- It was shown that the aloe gel, once extracted from the leaf, had greater stability than the gel left in the leaf. In order to avoid the decomposition of the biological activity, the filleting operation must be completed within $36 \mathrm{hrs}$. Of harvesting the leaves.

- Grinding/homogenization- The major steps in this process include crushing or grinding. The aloe gel fillets should be crushed and homogenized using a commercial high speed tissue crusher at room temperature $\left(25^{\circ} \mathrm{C}\right)$. And add agar agar into the mixture.

- Addition of vitamin E- The unpasteurized aloe gel juice was fortified with vitamin $\mathrm{E}$ to improve the flavor of Aloe vera gel juice and to stabilize the juice. It is used for its antioxidant activity.

- Pasteurization- Treatment (at $85-95^{\circ} \mathrm{C}$ for $1-2 \mathrm{~min}$ ) is an effective method to avoid the bad flavor and the loss of biological activity of the Aloe vera gel.

- Flash cooling- After pasteurization, the juice is flash cooled to $5^{\circ} \mathrm{C}$ or below within $10-15 \mathrm{sec}$. This is a crucial step to preserve biological activity of the Aloe vera gel.

- Storage- Relative humidity and temperature are two most important environmental parameters that affect product quality.

- Formulation method of lotion:- Measure the quantity of above formulated gel. Weigh all other ingredient used in formulation. Take a large glass or plastic mixing bowl. Add measured out gel of the aloe vera into the mixing bowl. Then add other ingredients of the formulation one by one like coconut oil, rosewater, vitamin E, glycerin, essential oil \& arrowroot powder with measured quantity. Mix all the ingredient of the bowl in vigorously manner. Herbal lotion was prepared.

\section{EVALUATION PARAMETER}

Spreadability- It is the term expressed to denote the extent of area to which formulation readily spreads on application to skin or affected part. The therapeutic efficacy of a formulation also depends upon its spreading value [16].

It is calculated by using the formula:

$$
\mathrm{S}=\mathrm{M} \text {. L / T }
$$

Where, $\mathrm{M}=$ weight tied to upper slide

$\mathrm{L}=$ length of glass slides

$\mathrm{T}=$ time taken to separate the slides

- Determination of $\mathrm{pH}-\mathrm{pH}$ of $1 \%$ aqueous solution of the formulation was measured by using a calibrated digital $\mathrm{pH}$ meter at constant temperature. $\mathrm{pH}$ value of the formulation is 5.5.

- Homogeneity- All developed gels were tested for homogeneity by visual inspection after the gels have 
been set in the container. They were tested for their appearance and presence of any aggregates.

- Viscosity- The measurement of viscosity of the prepared gel was done with a Brookfield viscometer spindle no.7 and speed 60rpm at $25 \cdot \mathrm{C}$.

- Smoothness- The smoothness of the lotion formulation was tested by rubbing between the fingers and observes whether the gel is smooth, clumped, homogenous or rough.

- Absorbency- Rated at which product is perceived to be absorbed into skin. Evaluated by noting changes in skin surface. Rated slow-moderated-fast.

- Consistency and Gressiness- They both was checked by applying on skin.

- Appearance- All the formulations of aloe vera lotion were light green.

- Washability- The product was applied on hand was observed under running water.

- Irritancy Test- The cream was applied on left hand dorsal side surface of 1 sq.cm and observed in equal intervals up to $24 \mathrm{hrs}$ for irritancy, redness and edema. The did not produce any irritation or redness on skin.

\section{APPLICATIONS}

\section{Application of body:}

- Helps digestion- Drinking Aloe vera juice it encourages the bowels to move and helps with elimination if a person is constipated. And if you have diarrhea, it will help slow it down.

- Builds immunity- Aloe vera juice stimulate macrophages, the white blood cells that fight viruses.

- Detoxifies- Aloe vera juice is a great natural aid to detox. Drinking Aloe vera juice provides a fantastically rich cocktail of vitamins, minerals and trace elements to help our bodies deal with these stresses and strains every day.

\section{Clinical application}

- Aphthous Ulcer- Researchers evaluated a gel that combined all antoin, Aloe vera, and silicon dioxide and its effects on aphthous ulcers of the oral cavity [9].

- Oral Lichen Planus- The efficiency of Aloe vera in treatment of oral lichen planus as been measured by many researchers [9].

- Gingivitis- Several studies have been conducted to test the efficacy of Aloe vera in treating gingivitis [9].

- Denture Adhesive- It is a property that led to the production of prototype cemannan denture adhesives.

- Cancer- Glyco proteins and polysaccharides present in Aloe vera make it a potent chemo-preventive agent that is useful against various types of cancers. These agents stimulate the immune system to fight against cancer.
- Antidiabetic- Aloe vera gel is an effective anti-hyperglycemic agent against type 2 diabetes. It lowers the blood glucose level without disturbing the normal blood lipid level and liver/kidney function.

- Asthma- Storage of Aloe vera extract in the dark for a period of 3-10days produces some active compounds prostanoids. These active compounds have shown effectiveness against chronic bronchial asthmatics.

- Cosmetic applications:- Aloe vera gel and powder have many other applications in the cosmetic industry due to their valuable moisturizing and soothing effects in products like shampoos, soaps, cleansers and moisturizing creams. Soaps prepared with Aloe vera have the advantage that they do not cause irritation and do not leave this kindry.

\section{RESULT AND DISCUSSION}

Aloe vera plant has potential in pharmaceutical, nutritional and cosmetic industries. The processing of Aloe vera requires critical attention in time, temperature and sanitation. The herbal gel and body lotion was prepared and subjected to evaluation of various parameters. The herbal formulation was greenish in color. The $\mathrm{pH}$ was constant throughout the study to about 5.5 which lies in the normal $\mathrm{pH}$ range of the skin and the gel did not produce any irritation upon application to the skin. Viscosity is the most important parameter in the evaluation as it governs the many properties of the formulation such as, spreadability, pourability of the product. The values of spreadability indicate that the gel is easily spreadable by small amount of shear. The measurement of extrudability becomes an important criterion. All Gel formulations had an excellent extrudability. The stability test was carried out for three months and results revealed that the all gels showed better stability. During stability study, there was not much variation in viscosity after testing at different temperature conditions. The preparation was stable under normal storage conditions. These results indicated that the herbal gel had no adverse effects on the topical area. It is showed this herbal preparation is useful in inflammation, wound healing and anti-aging.

\section{ACKNOWLEDGEMENT}

Authors are thankful to assistant professor Dr. Dharmesh Sisodiya sir for guidance and Head of Department Dr. Kamlesh Dashora sir Institute of Pharmacy Ujjain M.P. for providing facilities for the research work.

\section{REFERENCES}

1. Atlaw T K. Preparation and Utilization of Natural Aloe Vera to Enhance Quality of Mango Fruit. 2018;6(3):76-81. 
2. Maana A A, Nazir A, Khan M K I, Ahmad T, Zia R, Murid M, Abrar M. The Therapeutic Properties And Applications of Aloe Vera: A Review. 2018:1-10.

3. Yohannes G. Review On Medicinal Value Of Aloe Vera In Veterinary Practice. 2018:01-06.

4. Mendhekar S Y, Thorat P B, Bodke N N, Jadhav SL, Gaikwadd D. Formulation And Evaluation Of Gel Containing Neem, Turmeric, Aloe Vera, Green Tea And Lemon Extract With Activated Charcoal And Honey. 2017;12(4):439-443.ISSN 394-3211.

5. Pardeshi $M$ D.Formulation And Evaluation Of Aloe-Vera Gel With Active Salt And Alum: As A New Dentifrice. 2016;6(5):297-310.

6. Pandey A, Singh S. Aloe Vera: A Systematic Review Of Its Industrial And Ethno-Medicinal Efficacy.2016;5(1):21-33.

7. Nia A F, Farhangsardrodi A. Morphological \& Physiologocal Changes of Aloe (Aloe Barbadensis Miller) In Response to Culture Media. 2015;6(6):100-105.

8. Bhuvana, Hema, Patil R T. Review On Aloe Vera.2014;2(3):677-691.

9. Sajjad A, Sajjad SS. Aloe Vera: An Ancient Herb for Modern dentistry-A Literature Review. 2014:01-06.

10. Periasamy, Kassa P, Sintayehu B, Libanos M, Gereziher G, Karim A. Cosmetic Use Of Aloe Vera - A Review. 2014;3(5):342-458.

11. Bal A, Tara, Deva A S, Madan J, Sharma S. Preparation And Evaluation Of Novel Aloe Vera Gel Beads. 2013;2(6):206-216.

12. Itrat M, Zarnigar. Aloe Vera: A Review of Its Clinical Effectiveness. 2013;4(8):75-79.

13. Scala K D, AntonioVegagálve $Z$, Ahen $K$, Nuñez-Mancilla Y, Munizaga G T, Pérez-Won M, Giovagnoli C. Chemical And Physical Properties Of Aloe Vera (Aloe Barbadensis Miller) Gel Stored After High Hydrostatic Pressure Processing. 2013:52-59.
14. Chandegara V, Varshney A K. Aloe Vera L. Processing And Product: A Review. 2013;3(4):492-506.

15. Sahu P K, Giri D D, Singh R, Pandey P, Gupta S, Shrivastava A K, Kumar A, Pandey K D. Therapeutic And Medicinal Uses Of Aloe Vera: A Review. 2013;4:599-610.

16. Singh M, Nagori B, Shaw N, Tiwari M, Hanwar B. Formulation Development \& Evaluation Of Topical Gel Formulations Using Different Gelling Agents And Its Comparison With Marketed Gel Formulation. 2013;3(3):1-10.

17. Rajeswari R, Umadevi M, Rahale S, Pushpa R, Selvavenkadesh, Kumar K S, Bhowmik D. Aloe Vera: The Miracle Plant Its Medicinal And Traditional Uses In India. 2012;1:118-124.

18. Maqbool S, Jairajpuri D, Bashir K. Preparation And Processing Of Orange Flavoured Aloevera Gel. 2012;1(5):40-43.

19. Pounikar Y, Jain P, Khurana N, Omray K, Patil S, Gajbhiye A. Formulation And Characterization Of Aloe Vera Cosmetic Herbal Hydrogel. 2012;4:85-86.

20. Khan A, Khan M, Iqbal, Bashir. Formulation Development and Moiturising Effects of a Topical Cream of Aloe Vera Extract. 2011;5(3):128-136.

21. Ahlawat K S, Khatkar B S. Processing, Food Applications and Safety of Aloe Vera Products: A Review. 2011;48(5):525-533.

22. Yagbemi TI, Azeez O. Assessment of Chronic Administration of Aloe Vera Gel On Haematology, Plasma Biochemistry, Lipid Profiles And Erythrocyte Osmotic Resistance In Wistar Rats. 2010:107-113.

23. Tambe R, Kulkarni M, Joice A, Gilani I. Formulation and Evaluation of Aloe Vera Gels. 2009;2(10):1588-1590.

24. Hamman J. Composition and Applications of Aloe Vera Leaf Gel.2008:1599-1616.

25. Ramachandra C, Rao S. Processing Of Aloe Vera Leaf Gel: A Review. 2008;3(2):Page 502-510. 